\title{
Modeling of Pharmaceutical Biotransformation by Enriched Nitrifying Culture under Different Metabolic Conditions
}

\author{
Xu, Yifeng; Chen, Xueming; Yuan, Zhiguo; Ni, Bing-Jie
}

Published in:

Environmental Science \& Technology

Link to article, DOI:

10.1021/acs.est.8b00705

Publication date:

2018

Document Version

Peer reviewed version

Link back to DTU Orbit

Citation (APA):

Xu, Y., Chen, X., Yuan, Z., \& Ni, B-J. (2018). Modeling of Pharmaceutical Biotransformation by Enriched Nitrifying Culture under Different Metabolic Conditions. Environmental Science \& Technology, 52(5), 2835-2843. https://doi.org/10.1021/acs.est.8b00705

\section{General rights}

Copyright and moral rights for the publications made accessible in the public portal are retained by the authors and/or other copyright owners and it is a condition of accessing publications that users recognise and abide by the legal requirements associated with these rights.

- Users may download and print one copy of any publication from the public portal for the purpose of private study or research.

- You may not further distribute the material or use it for any profit-making activity or commercial gain

- You may freely distribute the URL identifying the publication in the public portal 


\title{
Article
}

Subscriber access provided by DTU Library

\section{Modeling of Pharmaceutical Biotransformation by Enriched Nitrifying Culture under Different Metabolic Conditions}

\author{
Yifeng Xu, Xueming Chen, Zhiguo Yuan, and Bing-Jie Ni
}

Environ. Sci. Technol., Just Accepted Manuscript • DOI: 10.1021/acs.est.8b00705 • Publication Date (Web): 15 Feb 2018

Downloaded from http://pubs.acs.org on February 20, 2018

\section{Just Accepted}

"Just Accepted" manuscripts have been peer-reviewed and accepted for publication. They are posted online prior to technical editing, formatting for publication and author proofing. The American Chemical Society provides "Just Accepted" as a service to the research community to expedite the dissemination of scientific material as soon as possible after acceptance. "Just Accepted" manuscripts appear in full in PDF format accompanied by an HTML abstract. "Just Accepted" manuscripts have been fully peer reviewed, but should not be considered the official version of record. They are citable by the Digital Object Identifier (DOI®). "Just Accepted" is an optional service offered to authors. Therefore, the "Just Accepted" Web site may not include all articles that will be published in the journal. After a manuscript is technically edited and formatted, it will be removed from the "Just Accepted" Web site and published as an ASAP article. Note that technical editing may introduce minor changes to the manuscript text and/or graphics which could affect content, and all legal disclaimers and ethical guidelines that apply to the journal pertain. ACS cannot be held responsible for errors or consequences arising from the use of information contained in these "Just Accepted" manuscripts. 
1 Modeling of Pharmaceutical Biotransformation by Enriched Nitrifying Culture under

\section{Different Metabolic Conditions}

3

$6{ }^{1}$ Advanced Water Management Centre, The University of Queensland, St. Lucia, Brisbane,

$$
\text { QLD 4072, Australia }
$$

9 Biochemical Engineering, Technical University of Denmark, 2800 Kgs. Lyngby, Denmark

\section{*Corresponding author:}

12 Phone: + 6173346 3219; Fax: +61 73365 4726; E-mail: bingjieni@gmail.com

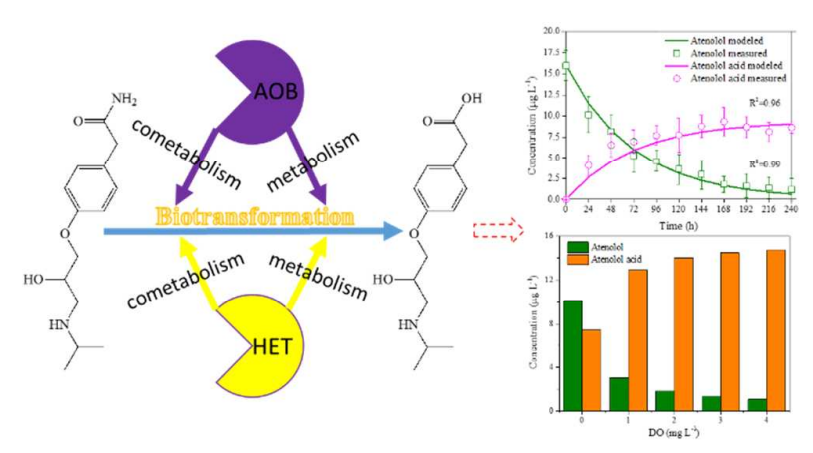




\section{Abstract}

19 Pharmaceutical removal could be significantly enhanced through cometabolism during 20 nitrification processes. So far pharmaceutical biotransformation models have not considered

21 the formation of transformation products associated with the metabolic type of 22 microorganisms. Here we reported a comprehensive model to describe and evaluate the 23 biodegradation of pharmaceuticals and the formation of their biotransformation products by 24 enriched nitrifying cultures. The biotransformation of parent compounds was linked to the 25 microbial processes via cometabolism induced by ammonium oxidizing bacteria (AOB) 26 growth, metabolism by AOB, cometabolism by heterotrophs (HET) growth and metabolism

27 by HET in the model framework. The model was calibrated and validated using experimental 28 data from pharmaceuticals biodegradation experiments at realistic levels, taking two 29 pharmaceuticals as examples, i.e., atenolol and acyclovir. Results demonstrated the good 30 prediction performance of the established biotransformation model under different metabolic 31 conditions, as well as the reliability of the established model in predicting different 32 pharmaceuticals biotransformations. The linear positive correlation between ammonia 33 oxidation rate and pharmaceutical degradation rate confirmed the major role of cometabolism 34 induced by AOB in the pharmaceutical removal. Dissolved oxygen was also revealed to be 35 capable of regulating the pharmaceutical biotransformation cometabolically and the substrate 36 competition between ammonium and pharmaceuticals existed especially at high ammonium 37 concentrations.

39 Keywords: Cometabolism, pharmaceutical, model, ammonia oxidizing bacteria, 40 biotransformation product, substrate competition 


\section{Introduction}

43 The ubiquitous occurrence and fate of pharmaceuticals in the environment and 44 engineering systems have attracted the concerns of the scientists and the public for decades 45 due to their potential ecotoxic impact on aquatic ecosystems. ${ }^{1,2}$ These organic compounds 46 were present in the wastewater at concentrations ranging from $\operatorname{pg~L}^{-1}$ to $\mu g \mathrm{~L}^{-1}$. 3,4 As the 47 wastewater treatment plants (WWTPs) were originally designed for chemical oxygen demand 48 and other nutrients removal, the incomplete removal was found for pharmaceuticals in the 49 treatment processes, being a major pathway for pharmaceuticals to enter the environment. ${ }^{5}$

50 Autotrophic biomass (e.g., enriched nitrifying sludge) was capable of transforming the 51 pharmaceuticals cometabolically during the wastewater treatment process and thus the 52 pharmaceutical removal was reported to be positively correlated to nitrification rate. ${ }^{6,7}$

53 Ammonia oxidizing bacteria $(\mathrm{AOB})$ in the nitrifying biomass could degrade a broad range of 54 substrates including aromatic and aliphatic compounds due to the non-specific enzyme 55 ammonia monooxygenase (AMO). ${ }^{8-10}$ The presence of the growth substrate (i.e. ammonium) 56 was required for cometabolism which should be taken into account when predicting the fate

57 of pharmaceuticals. ${ }^{11}$ In addition to cometabolism, pharmaceuticals could also be degraded as 58 the energy and carbon source for microorganisms through metabolic biotransformation. ${ }^{11}$

59 Furthermore, the formed biotransformation products might be more toxic and persistent. ${ }^{12}$ 60 Hence the biotransformation products should be considered for a more comprehensive 61 understanding of the fate of pharmaceuticals in the nitrifying activated sludge.

62 Mathematical modeling offers a useful tool and is adopted widely to analyze complicated 63 metabolic pathways. Cometabolic biotransformations were previously modeled through first64 order kinetics and mixed order kinetics like Monod expression ${ }^{13-15}$ and have evolved from 65 only considering the cometabolic substrates to incorporating the relationships between 66 cometabolic substrates and growth substrates, such as competitive interaction and toxicity 
67 inhibition. $^{15}$ However, the previous literature has rarely considered the formation of 68 biotransformation products in the cometabolic biotransformation models for pharmaceuticals.

69 The aim of this work is to develop and test a comprehensive modeling framework to 70 describe the pharmaceuticals biotransformation at realistic levels as well as the formation of 71 their biotransformation products by the enriched nitrifying sludge under different metabolic 72 conditions. Microbial processes contributing to the pharmaceutical biotransformation were 73 considered as follows: growth-linked cometabolism by AOB, metabolic transformation by 74 AOB, growth-linked cometabolism by heterotrophs (HET) and metabolic transformation by 75 HET. To this end, atenolol and acyclovir were selected as the model compounds in this study 76 as they were frequently found in the wastewater with the highest concentrations of 25 and 1.8 $77 \mu \mathrm{g} \mathrm{L} \mathrm{L}^{-1}$, respectively, which have been reported to be increasingly removed under nitrifying 78 conditions. ${ }^{16-18}$ It has been reported that they can be biotransformed into atenolol acid and 79 carboxy-acyclovir, respectively. ${ }^{18,19}$ Model calibration and validation were carried out with 80 experimental data using atenolol as parent compounds under different metabolic conditions.

81 Model evaluation was also conducted using the experimental data from acyclovir 82 biotransformation. The effects of dissolved oxygen (DO) and ammonium concentrations on 83 pharmaceutical biotransformation were investigated using the validated model to provide 84 insights into the process dynamics. The reported model in this work is expected to be used as 85 a tool to fully understand the fate of pharmaceuticals associated with different metabolisms 86 by responsible microorganisms in the complicated activated sludge system.

\section{Materials and Methods}


91 A multi-species and multi-substrate model was developed to describe the pharmaceutical 92 biotransformation processes by the enriched nitrifying sludge. This biotransformation model 93 comprehensively considered the consumption of the pharmaceuticals and the formation of 94 transformation products accompanied with the simultaneous nitrification in the enriched 95 nitrifying sludge. It describes the relationships among eight soluble substrates as defined in 96 Table S1 in Supporting Information (SI), i.e., ammonium $\left(S_{\mathrm{NH}_{4}}\right)$, nitrite $\left(\mathrm{S}_{\mathrm{NO}_{2}}\right)$, nitrate $\left(\mathrm{S}_{\mathrm{NO}_{3}}\right)$, 97 readily biodegradable substrates $\left(S_{S}\right)$, oxygen $\left(S_{O_{2}}\right)$, pharmaceutical (parent compound, PC, $\left.98 S_{P C}\right)$, primary biotransformation product $\left(\mathrm{BP}, S_{B P}\right)$ and other biotransformation products (OP, $\left.99 S_{O P}\right)$, and five particulate species, i.e., AOB $\left(X_{A O B}\right)$, HET $\left(X_{H E T}\right)$, NOB (nitrite oxidizing 100 bacteria, $\left.X_{N O B}\right)$, slowly biodegradable substrates $\left(X_{S}\right)$ and inert biomass $\left(X_{I}\right)$. Nine processes 101 are considered: (1) metabolic transformation of PC by AOB; (2) cometabolic transformation 102 of PC coupled to growth of AOB; (3) endogenous decay of AOB; (4) hydrolysis; (5) 103 metabolic transformation of PC by HET; (6) cometabolic transformation of PC coupled to 104 growth of HET; (7) endogenous decay of HET; (8) growth of NOB; and (9) endogenous 105 decay of NOB. The kinetic expressions and the stoichiometric matrix of the proposed 106 biotransformation model are summarized in Tables S2 and S3 in SI, respectively. The 107 definitions, values, units and sources of all parameters used in the biotransformation model 108 are listed in Table S4 in SI.

109 Pharmaceutical biodegradation was reported to be linked to AOB due to the non-specific 110 enzyme AMO as well as HET, which was not related to the activity of NOB. ${ }^{20}$ In this model, 111 the microbial growth-linked kinetic expressions (processes 2 and 6 in Table S2 in SI) are 112 described using the Monod equations, which are associated with cometabolic 113 biotransformation of pharmaceuticals. ${ }^{20}$ The concentration of growth substrates $S_{N_{4}}$ and $S_{S}$ 114 is also involved in the Monod equations. The basis of the cometabolic biotransformation 115 expressions is the concept of transformation coefficient parameters such as AOB growth- 
116 linked $T_{P C-A O B}^{c}$ and HET growth-linked $T_{P C-H E T}^{c}$. The pharmaceutical biotransformation

117 reactions directly conducted via metabolism by AOB and HET are described by pseudo-first

118 order kinetic expressions (processes 1 and 5 in Table S2 in SI). For each reaction, the rate is

119 expressed by an explicit function of the concentrations of relevant pharmaceuticals in the

120 process. For microbial metabolic biodegradation of $\mathrm{PC}$, the key parameters are biomass

121 normalized PC degradation rate coefficients in the absence of AOB and HET growth, i.e.

$122 k_{P C-A O B}$ and $k_{P C-H E T}$. Processes $1,2,5$ and 6 together contribute to pharmaceutical

123 biotransformation in the enriched nitrifying sludge.

124 The formation of biotransformation products is modeled using the specific stoichiometry

125 coefficients in processes 1, 2, 5 and 6 . The coefficients $\alpha_{B P}^{m}$ and $\alpha_{B P}^{c}$ indicate the

126 transformation of $\mathrm{PC}$ to $\mathrm{BP}$ under metabolism and cometabolism conditions by $\mathrm{AOB}$,

127 respectively. Similarly, the coefficients $\beta_{B P}^{m}$ and $\beta_{B P}^{c}$ present the transformation of PC to BP

128 under metabolism and cometabolism conditions by HET, respectively.

\section{Atenolol and acyclovir biotransformation experiments}

131 Experimental data from our previous biodegradation experiments of atenolol (Case $I$ )

132 and acyclovir (Case II) under different conditions by an enriched nitrifying sludge were used

133 for model evaluation in this work. ${ }^{21,22}$ The chemicals used in the batch experiments and the

134 enrichment of nitrifying cultures in the sequencing batch reactor (SBR) are described in Text

135 S1 and S2 in SI. Details of the experimental conditions applied in different scenarios are

136 provided in Table S5 in SI. Briefly, 4-L beaker was used as the batch reactor with enriched

137 nitrifying cultures inoculated to degrade parent compounds at an initial $15 \mu \mathrm{g} \mathrm{L}^{-1}$. The mixed

138 liquid suspended solid (MLVSS) concentration was kept at approximately $1 \mathrm{~g} \mathrm{~L}^{-1}$. All the

139 batch experiments were conducted in duplicates. The designs for Experiments 1-3 were same

140 for atenolol (Case $I$ ) and acyclovir (Case $I I$ ). In Experiment 1, $30 \mathrm{mg} \mathrm{L}^{-1}$ allylthiourea (ATU) 
141 was added to inhibit nitrifying activities, ${ }^{20,23,24}$ leading to the dominant contribution from

142 HET to pharmaceutical biotransformation. ${ }^{11}$ Initial ammonium concentration was provided at

$14350 \mathrm{mg}-\mathrm{N} \mathrm{L}^{-1}$. No external ammonium was supplied during the entire experimental period

144 (240 h). In Experiment 2, no initial and external ammonium was provided during 240 h. In

145 Experiment 3, constant ammonium concentration was maintained at $50 \mathrm{mg}-\mathrm{N} \mathrm{L}^{-1}$ by dosing a

146 mixture of ammonium bicarbonate and potassium bicarbonate as ammonium feeding solution

147 and $\mathrm{pH}$ buffer at the same time, which could ensure the cometabolic biotransformation by

148 AOB. The Experiment 4 was exclusively designed for atenolol biotransformation, where

149 constant ammonium concentrations of $25 \mathrm{mg}-\mathrm{N} \mathrm{L}^{-1}$ were provided using the dosing method

150 in Experiment 3 during the experimental period. Samples were collected periodically to

151 analyse mixed liquid suspended solid (MLSS) concentration and its volatile fraction (i.e.,

152 MLVSS), $\mathrm{NH}_{4}^{+}, \mathrm{NO}_{2}^{-}, \mathrm{NO}_{3}^{-}$, atenolol, acyclovir and their biotransformation products

153 atenolol acid and carboxy-acyclovir. The detailed chemical analysis procedures could be

154 found in the previous work. ${ }^{21,22,25}$

155 The contribution of sorption to removal of atenolol and acyclovir was insignificant based

156 on our previous studies. ${ }^{22,25}$ This is in consistent with low sorption coefficient $K_{D}(0.04)$ of

157 atenolol and low octanol-water partition coefficient $\log K_{O W}(0.16)$ of atenolol as well as Log

$158 K_{O W}(-1.59)$ of acyclovir. ${ }^{26-28}$ Volatilization was considered negligible given the low values of

159 Henry's law constants for atenolol $\left(1.37 \times 10^{-18} \mathrm{~atm} \mathrm{~m}^{3} \mathrm{~mol}^{-1}\right)$ and acyclovir $\left(3.2 \times 10^{-22} \mathrm{~atm} \mathrm{~m}^{3}\right.$

$\left.160 \mathrm{~mol}^{-1}\right) .{ }^{29}$ Hydrolysis would not contribute to the degradation of atenolol and acyclovir, which

161 was confirmed previously and was in consistent with the absence of their transformation

162 products. ${ }^{22,25}$ Photodegradation was also insignificant considering the turbidity of the sludge

163 and the aluminum foil covering the reactor. Therefore, microbially induced biodegradation

164 should be the main mechanism for pharmaceutical removal in both atenolol and acyclovir

165 biotransformation experiments. 


\section{Model calibration and validation}

168 The biotransformation model used in this work consists of 9 biochemical processes and 16927 stoichiometric and kinetic parameters (as shown in Tables S2 and S4 in SI). Most of these 170 parameters were well established in previous literature, therefore the reported values were

171 directly used in this developed model. However, the information on biomass growth-linked 172 PC transformation coefficients $T_{P C-A O B}^{c}$ and $T_{P C-H E T}^{c}$ and microbial endogenous

173 transformation coefficients $k_{P C-A O B}$ and $k_{P C-H E T}$ was limited. ${ }^{20}$ Considering the key role of 174 cometabolism induced by AOB growth in biotransformation, the maximum specific growth 175 rate of $\mathrm{AOB} \mu_{\max , A O B}$ was of significance to the developed model. Furthermore, the 176 sensitivity analysis suggested the four key parameters $k_{P C-A O B}, k_{P C-H E T}, T_{P C-A O B}^{c}$ and $\mu_{\max , A O B}$ 177 are highly sensitive to the biotransformation processes in terms of the experimental 178 measurements (examples shown in Figure S1 in SI). Model calibration was therefore 179 conducted to estimate the values of $k_{P C-A O B}, k_{P C-H E T}, T_{P C-A O B}^{c}$ and $\mu_{\max , A O B}$ based on 180 experimental measurements through minimizing the sum of squares of the deviations 181 between the measured and modeled values for the concentrations of parent compounds and 182 biotransformation products under different conditions. In addition, the four stoichiometric 183 coefficients, i.e., $\alpha_{B P}^{m}, \alpha_{B P}^{c}, \beta_{B P}^{m}$ and $\beta_{B P}^{c}$, for the transformation of PC to BP under metabolism 184 and cometabolism conditions could be determined based on the respective molecular mass 185 and concentrations of BP and PC measured in the experiments.

186 Experimental data from atenolol biotransformation (Case I) of Experiments 1-3 were 187 firstly used for model calibration. Concentrations of ammonium, nitrite, DO, atenolol and 188 atenolol acid from Experiment 1 and Experiment 2 were fitted by model simulations to 189 estimate $k_{P C-H E T}$ and $k_{P C-A O B}$, respectively, whereas concentrations of ammonium, nitrite, DO, 
190

191

192

193

194

195

196

197

200

201

202

203

204

205

206

207

\section{Results \\ Results}

213

214 Model calibration with experimental data from atenolol biotransformation using the $k_{P C-H E T}$ and $k_{P C-A O B}$ values obtained in previous experiments (Experiment 1 and Experiment 2). Model validation was then carried out with the calibrated parameters using the independent experimental data sets from atenolol biotransformation of Experiment $4 .^{21}$ Specifically, in Experiment 4, batch experiments with atenolol as the parent compound at an initial concentration of $15 \mu \mathrm{g} \mathrm{L}^{-1}$ were conducted using the same enriched nitrifying sludge (i.e., same microbial composition) in the constant presence of ammonium of $25 \mathrm{mg}-\mathrm{N} \mathrm{L}{ }^{-1}$ and at DO of around $2.5 \mathrm{mg} \mathrm{L}^{-1}$. There were no significant gaps between batch experiments, leading to insignificant biomass changes. The ammonium and DO concentrations applied were different from of Experiment 3 at ammonium of $50 \mathrm{mg}-\mathrm{N} \mathrm{L}^{-1}$ and DO of $3.0 \mathrm{mg} \mathrm{L}^{-1}$ (Table S5 in SI). To further verify the validity and applicability of the model, the model was also applied to evaluating the acyclovir biotransformation data from Case $I I$ of Experiments 1-3. The key model parameters were recalibrated for Case $I I$ using the three sets of batch experimental data (Table S5 in SI).

The sensitivity analysis, parameter estimation, parameter uncertainty evaluation and model simulations were done through employing a modified version of software AQUASIM 2.1d according to Batstone et al. ${ }^{30}$, with a $95 \%$ confidence level for significance testing and parameter uncertainty analysis. The standard errors and $95 \%$ confidence intervals of individual parameter estimates were calculated from the mean square fitting errors and the sensitivity of the model to the parameters. Residual sum of squares (RSS) between the objective data and model was used as the objective function.

atenolol and atenolol acid from Experiment 3 were fitted to estimate $\mu_{\max , A O B}$ and $T_{P C-A O B}^{c}$, 
215 As atenolol acid was the sole biotransformation products with no other products

216 identified in all batch experiments, the dynamics of the substrate $S_{O P}$ was not modeled herein.

217 The model was first calibrated to illustrate the biotransformation of atenolol catalysed solely

218 by HET in Experiment 1 (i.e. with addition of ATU to inhibit the nitrifying activity). Given

219 that no exogenous organic carbon was supplied during culture enrichment and the only

220 organic carbon in the batch experiments was pharmaceuticals, the growth of HET was

221 considered extremely low and the cometabolic transformation rate of pharmaecuticals linked

222 to growth of HET was not modeled with $T_{P C-H E T}^{c}$ omitted for estimation. ${ }^{20}$ With AOB related

223 parameters $k_{P C-A O B}$ and $T_{P C-A O B}^{c}$ set to zero, only the parameter $k_{P C-H E T}$ was estimated with

224 its best-fit value shown in Table 1 for Experiment 1. The predicted atenolol and atenolol acid

225 concentration profiles with the established model were demonstrated in Figure 1A, along

226 with the measured experimental values. Atenolol experienced a continuous decrease by $94.3 \%$

227 from the beginning to the end of experiments accompanied with a gradual increase of

228 atenolol acid until $168 \mathrm{~h}$ and a stable stage until $240 \mathrm{~h}$ at a conversion efficiency of $62.6 \%$

229 (Figure 1A), which was well captured by the model predictions.

230 The experimental data obtained from Experiment 2 (i.e., in the absence of ammonium)

231 were used to further calibrate the developed model in terms of atenolol and atenolol acid

232 dynamics. Without the presence of the growth substrate, the ammonium released from cell

233 lysis process during bacterial decay was minor and AOB growth-linked cometabolism would

234 be considered to have negligible contribution to atenolol biotransformation. Therefore, only

235 the metabolic biotransformation by AOB and HET were involved in the biotransformation of

236 atenolol for Experiment 2. The parameter value of $k_{P C-H E T}$ obtained in Experiment 1 was

237 used directly without any modification. Another key model parameter $k_{P C-A O B}$ related to AOB

238 metabolism was thus reliably estimated during atenolol biotransformation (value as shown in

239 Table 1). As shown in Figure 1B, although atenolol demonstrated a sharp decrease by $97.4 \%$ 
240 over the whole experimental period, the production of atenolol acid indicated a lower 241 transformation efficiency in the absence of ammonium (29.1\%) compared with the 242 experiments with addition of ATU (see Figure 1A), again well matching the model 243 predictions.

244 In Experiment 3, the presence of ammonium at $50 \mathrm{mg}-\mathrm{N} \mathrm{L}^{-1}$ was provided constantly to 245 ensure the cometabolic biodegradation of atenolol by both AOB and HET at DO of $3.0 \mathrm{mg} \mathrm{L}^{-}$

2461 . Together with the rest of the parameters involved, the parameter values of $k_{P C-H E T}$ and $247 k_{P C-A O B}$ estimated in the previous two experiments were applied in the biotransformation 248 model. The key parameters related to AOB induced cometabolism, i.e., $T_{P C-A O B}^{c}$ and $\mu_{\max , A O B}$, 249 were then estimated with the optimum values listed in Table 1. Figure S2A in SI showed the 250 well agreement between predicted and measured concentrations of ammonium, nitrite and 251 DO based on the proposed model, supporting the capability of the model to describe the two252 step nitrification processes in terms of nitrite accumulation, as well as the suitability of the 253 selected parameters related to DO dynamics for the cometabolic biodegradation processes by 254 the enriched nitrifying culture (i.e., the $K_{O_{2}, A O B}$ and $K_{O_{2}, H E T}$ values for AOB and HET). It 255 should be noted that the nitrate concentrations were not specifically modeled, which were 256 slightly higher than that in the SBR in all experiments since the biomass in batch experiments 257 was taken directly from SBR with a background nitrate concentration up to $1000 \mathrm{mg} \mathrm{L}^{-1}$. As 258 shown in Figure 1C, concomitant with the gradual decrease of atenolol at a removal 259 efficiency of $88.0 \%$, atenolol acid was formed at an increasing trend with $86.9 \%$ conversion 260 efficiency. This was obviously higher than the experiments in the absence of ammonium and 261 with the addition of ATU, indicating a positive role of AOB induced cometabolism in 262 atenolol transformation. The model described these observations reasonably well.

263 Overall, the developed model could satisfactorily capture all dynamics associated with 264 atenolol and atenolol acid in all batch biodegradation experiments under different metabolic 
265 conditions. The good agreement between model simulations and measured data in Figure 1

266 supports the capability of the developed model in describing the microbial growth related

267 biotransformation of atenolol in enriched nitrifying cultures. The obtained parameter linked

268 to AOB growth during ammonia oxidation, i.e., AOB-induced cometabolic atenolol

269 transformation coefficient $T_{P C-A O B}^{c}$, was estimated at $0.012 \pm 0.000036 \mathrm{~m}^{3} \mathrm{~g} \mathrm{COD}^{-1}$. It was

270 lower than the reported value of $0.0715 \pm 0.0227 \mathrm{~m}^{3} \mathrm{~g} \mathrm{COD}^{-1}$ for atenolol biodegradation by

271 an enriched nitrifying sludge. ${ }^{20}$ The non-growth metabolism by HET and the non-growth

272 metabolism by AOB on atenolol biodegradation also described the experimental data with the

273 addition of ATU and in the absence of ammonium well. The estimated parameters of $k_{P C-H E T}$

274 and $k_{P C-A O B}$ were $0.000180 \pm 0.000017$ and $0.000140 \pm 0.000012 \mathrm{~m}^{3} \mathrm{~g} \mathrm{COD}^{-1} \mathrm{~h}^{-1}$, which were

275 lower than but in the same order of magnitude as the literature reported values $(0.00093 \pm$

2760.00018 and $0.00067 \pm 0.00023 \mathrm{~m}^{3} \mathrm{~g} \mathrm{COD}^{-1} \mathrm{~h}^{-1}$, respectively). ${ }^{20}$ The discrepancy in these

277 parameters values could be probably ascribed to the difference in the community structure in

278 the adopted nitrifying cultures or different operating conditions. The model could be

279 potentially applied to a widespread extent despite that the parameter values would vary

280 according to the experimental conditions. As suggested, it was difficult to compare these

281 coefficients $\left(k_{P C-H E T}, k_{P C-A O B}\right.$ and $\left.T_{P C-A O B}^{c}\right)$ with other pharmaceuticals as most existing

282 models did not consider the specific biochemical processes. ${ }^{20}$

\section{Model validation with atenolol biotransformation under different conditions}

285 In order to further confirm the validity and reliability of the developed model, model

validation was carried out to compare the model simulations to the independent experimental

287 data, which were not used for model calibration. Based on the measured concentrations of 288 atenolol and atenolol acid, the stoichiometric coefficients $\alpha_{B P}^{c}$ and $\alpha_{B P}^{m}$ were calculated as 0.58

289 and 0.58 , respectively. Applied with previously calibrated parameters in Table 1, the 
290 proposed biotransformation model was used to predict dynamics of ammonium, nitrite, DO, 291 atenolol and atenolol acid in the presence of ammonium at a constant concentration of $25 \mathrm{mg}$ -

$292 \mathrm{~N} \mathrm{~L}^{-1}$ and at DO of around $2.5 \mathrm{mg} \mathrm{L}^{-1}$ (significantly different from the ammonium of $50 \mathrm{mg}$ -

$293 \mathrm{~N} \mathrm{~L}^{-1}$ and DO of $3.0 \mathrm{mg} \mathrm{L}^{-1}$ used for model calibration). The model captured the dynamics of 294 ammonium, nitrite and DO, again suggesting the validity of the two-step nitrification model 295 and the suitability of the selected parameters related to DO (see Figure S2B). As shown in 296 Figure 2, atenolol continuously dropped from initial $15 \mu \mathrm{g} \mathrm{\textrm {L } ^ { - 1 }}$ with a final degradation 297 efficiency of $92.9 \%$. The conversion rate of atenolol acid transformed from atenolol was 298 calculated as $57.9 \%$. The model predictions could capture these trends of atenolol 299 degradation and atenolol acid formation very well, which again supports the validity of the 300 developed model for atenolol biotransformation.

\section{Model evaluation with experimental data from acyclovir biotransformation}

303 The experimental results obtained with Case II for biotransformation of acyclovir were 304 used to further evaluate the developed model. The developed biotransformation model was 305 recalibrated for acyclovir biodegradation and carboxy-acyclovir formation dynamics under different conditions. Most of the literature reported model parameters were employed at same values as the case of atenolol except the stoichiometry coefficients $\left(\alpha_{B P}^{m}, \alpha_{B P}^{c}, \beta_{B P}^{m}, \beta_{B P}^{c}\right)$ for

308 formation of carboxy-acyclovir associated with specific biochemical processes (as shown in 309 Table S4 in SI), which were calculated based on the experimental data. The values for the

310 three key parameters $k_{P C-H E T}, k_{P C-A O B}$ and $T_{P C-A O B}^{c}$ were recalibrated, which were associated 311 with the investigated parent compound. As the enriched nitrifying biomass utilized in the 312 batch biodegradation experiments of acyclovir were same as those in case of atenolol, the 313 maximum growth rate of $\mathrm{AOB} \mu_{\max , A O B}$ was set to be the same as in case of atenolol during model calibration for acyclovir biotransformation in the presence of ammonium. The 
315 obtained parameter values for acyclovir biotransformation were $0.00035 \pm 0.00002 \mathrm{~m}^{3} \mathrm{~g}$

$316 \mathrm{COD}^{-1} \mathrm{~h}^{-1}\left(k_{P C-H E T}\right), 0.00005 \pm 0.00003 \mathrm{~m}^{3} \mathrm{~g} \mathrm{COD}^{-1} \mathrm{~h}^{-1}\left(k_{P C-A O B}\right)$ and $0.00093 \pm 0.00049 \mathrm{~m}^{3} \mathrm{~g}$

$317 \operatorname{COD}^{-1}\left(T_{P C-A O B}^{c}\right)$.

318 The model predictions of acyclovir biotransformation matched the experimental results 319 well under different conditions (Figure 3), further demonstrating the validity of the 320 established model. Parameters values giving the optimum fits with the experimental data 321 were difficult to compare reliably with literature values as this study firstly reported the AOB 322 cometabolic acyclovir transform coefficient $T_{P C-A O B}^{c}$. However, compared to other reported 323 compounds, e.g. atenolol, ${ }^{20}$ it was obvious that parameters $k_{P C-A O B}$ and $T_{P C-A O B}^{c}$ for acyclovir 324 were lower than those values for atenolol (Table 1), indicating a stronger degradation ability 325 of the AOB culture studied on atenolol than acyclovir. Considering the molecular differences 326 between these two pharmaceuticals, this may imply an affinity property of AOB for different 327 compounds probably due to a preferential substrate selection to AMO active sites. ${ }^{31}$ The 328 parameter $k_{P C-H E T}$ for acyclovir was $0.00035 \pm 0.00002 \mathrm{~m}^{3} \mathrm{~g} \mathrm{COD}^{-1} \mathrm{~h}^{-1}$, which was in the 329 same order of magnitude of the value estimated in this study $\left(0.000180 \pm 0.000017 \mathrm{~m}^{3} \mathrm{~g}\right.$ $330 \mathrm{COD}^{-1} \mathrm{~h}^{-1}$ ) for atenolol. The conversion efficiencies from acyclovir to carboxy-acyclovir 331 were $83.9 \%, 43.0 \%$ and $29.9 \%$ in Experiments 1, 2 and 3, respectively (see Figure 3). These 332 results indicated the importance of metabolism of acyclovir by HET. Oxidation of acyclovir 333 to carboxy-acyclovir might be dominated by unspecific monoxygenase from HET, ${ }^{32}$ which 334 needs to be confirmed in the further work.

\section{Discussion}

337 In this work, a comprehensive mathematical model is developed to describe the 338 biotransformation of pharmaceuticals and the formation of their products by enriched 339 nitrifying cultures. In the proposed model, processes 1 and 2 (Table S2 in SI) depict the 
340 AOB-induced cometabolic and metabolic biotransformation of pharmaceuticals, while

341 processes 5 and 6 (Table S2 in SI) describe the HET-induced cometabolic and metabolic 342 biotransformation of pharmaceuticals, respectively. Sensitivity analysis indicated that four

343 key parameters $k_{P C-H E T}, k_{P C-A O B}, T_{P C-A O B}^{c}$ and $\mu_{\max , A O B}$ were critical to the model output and 344 therefore estimated through model calibration. The validity of this biotransformation model is 345 confirmed by independent atenolol biodegradation data and further evaluated by acyclovir 346 biotransformation experiments. Compared to the previous studies where atenolol 347 biodegradation was investigated through experiments and modeling approaches, ${ }^{20,21}$ the 348 proposed model in this work considers the formation of biotransformation products and 349 describes biotransformation of different pharmaceuticals under different metabolic conditions. 350 This microbial processes-linked biotransformation model could enhance our ability to predict 351 the fate of pharmaceuticals and their transformation products during wastewater treatment 352 processes.

353 Since we estimated four model parameters for fitting the experimental data, parameter 354 uniqueness is important, since it is possible that different parameter combinations can give 355 similar simulation accuracy. In our work, we applied a least-squared analysis and evaluated 356 standard errors and 95\% confidence intervals of individual parameter estimates. The 357 parameter confidence intervals showed a well-defined range in which the optimum values of 358 parameters reside (Table 1), which indicates good uniqueness of these parameters. In addition 359 to the analysis of the confidence intervals, two other aspects of our experimental design 360 support the uniqueness of the parameter values. First, we used five different experimental 361 parameters (ammonium, nitrite, DO, parent compound, and biotransformation product), 362 which reflect different aspects of the kinetics of the two-step nitrification and pharmaceutical 363 biotransformation by enriched nitrifying culture. Second, we carried out independent 364 experiments to validate the estimated parameters. In particular, the good correspondence for 
365 independent experimental data supports the validity of the new model and the uniqueness of 366 the parameters for pharmaceutical biotransformation.

367 The modeling results in this work suggested the cometabolism induced by AOB could 368 play an important role in the pharmaceutical removal in the studied ratio ranges of 369 pharmaceuticals to ammonia for cometabolism. Indeed a positive linear relationship was 370 observed between ammonia oxidation rate and pharmaceutical degradation rates in terms of 371 atenolol and acyclovir based on the validated model (Figure 4A). The atenolol degradation 372 rate increased from 0.012 to $0.16 \mu \mathrm{g} \mathrm{g} \mathrm{VSS}{ }^{-1} \mathrm{~h}^{-1}$ while the nitrification rate increased from 3732.84 to $59.15 \mathrm{mg} \mathrm{NH}_{4}{ }^{+}-\mathrm{N} \mathrm{g} \mathrm{VSS}^{-1} \mathrm{~h}^{-1}$. With respect to acyclovir, the degradation rate changed 374 from 0.014 to $0.10 \mu \mathrm{g} \mathrm{VSS}^{-1} \mathrm{~h}^{-1}$ whereas the ammonia oxidation rate showed an increase 375 from 2.37 to $36.63 \mathrm{mg} \mathrm{NH}_{4}{ }^{+}-\mathrm{N} \mathrm{g} \mathrm{VSS}^{-1} \mathrm{~h}^{-1}$. Such a positive correlation was also reported in 376 previous literature under certain conditions, ${ }^{7,22,25}$ supporting the notion that majority of 377 atenolol and acyclovir could be cometabolically degraded in the enriched nitrifying cultures.

378 A further assessment on the wide application of the relationship was carried out by 379 simulating the concentration profiles of pharmaceuticals after $240 \mathrm{~h}$. The molar ratios of 380 atenolol to ammonia from $8.42 \times 10^{-7}$ to $1.91 \times 10^{-5}$ calculated based on their concentrations 381 was observed to be still within the range for a linearly positive relationship regarding the 382 cometabolic biodegradation of atenolol by the enriched nitrifying cultures used in this work, 383 and the relationship maintained at a same slope (Black solid squares in Figure 4A 384 demonstrated the predicted atenolol degradation rate after 240 h). However, a different slope 385 was found for the relationship between ammonia oxidation rate and the acyclovir degradation 386 rate after $240 \mathrm{~h}$ predicted using the developed model (Figure $4 \mathrm{~B}$ ). If the ammonia oxidation 387 rate was higher than the critical value $\left(2.3 \mathrm{mg} \mathrm{NH}_{4}^{+}-\mathrm{N} \mathrm{g} \mathrm{VSS}{ }^{-1} \mathrm{~h}^{-1}\right.$ in this study), the lower 388 slope might indicate a slower increasing trend in acyclovir degradation rate with an 389 increasing ammonia oxidation rate (Figure 4A). Compared with the situation at the lower 
390 ammonia oxidation rate, a higher increasing trend in acyclovir degradation rate would arise at 391 higher slope (Figure 4B). The observation that pharmaceutical would not be degraded until 392 the ammonia was depleted ${ }^{33}$ revealed a higher pharmaceutical degradation rate at lower 393 ammonia oxidation rate, which supported the findings in this study. Regardless of the 394 different slopes for the relationship, the molar ratios of acyclovir to ammonia ranging from $3951.62 \times 10^{-11}$ to $2.26 \times 10^{-5}$ was obtained to be a valid application range for the cometabolic 396 biodegradation of acyclovir by the enriched nitrifying cultures used in this work.

397 The proposed model framework was expected to be a useful tool to predict the 398 biotransformation of pharmaceuticals and the formation of transformation products under 399 varying conditions, therefore providing the guidance in designing, upgrading and optimizing 400 of the relevant biological wastewater treatment processes. The influence of DO on 401 pharmaceutical biotransformation was investigated by performing model simulations in the 402 enriched nitrifying systems. The pharmaceutical removal efficiencies at $240 \mathrm{~h}$ at different DO 403 concentrations ranging from 0 to $4 \mathrm{mg} \mathrm{L}^{-1}$ with ammonium concentration of $50 \mathrm{mg}-\mathrm{N} \mathrm{L}^{-1}$ are 404 shown in Figure 5. Overall DO concentration had a positive effect on pharmaceutical 405 removal efficiencies. The concentrations of atenolol and acyclovir decreased rapidly with a 406 prompt increase of atenolol acid and carboxy-acyclovir as DO increased to $1 \mathrm{mg} \mathrm{L}^{-1}$. With 407 DO further increased to $4 \mathrm{mg} \mathrm{L}^{-1}$, a gradual decrease of pharmaceutical concentrations was 408 observed accompanied with a slight increase of their biotransformation products. The 409 degradation efficiencies for atenolol at DO concentrations of 0,1 and $4 \mathrm{mg} \mathrm{L}^{-1}$ were $44.3 \%$, $41083.2 \%$ and $94.0 \%$, respectively. With regard to acyclovir, its degradation efficiencies were 411 observed to be $36.2 \%, 81.2 \%$ and $87.3 \%$, respectively at DO of 0,1 and $4 \mathrm{mg} \mathrm{L}^{-1}$. The 412 simulation results revealed that the DO concentration would play an important role in 413 pharmaceutical biotransformation. This was contrary to the previous report that DO in the 414 WWTP had no influence on oxidative biotransformation of selected micropollutants. ${ }^{34}$ The 
415 possible reason could be that the experiments conducted in this study were nitrifying culture

416 based instead of the regular activated sludge in WWTP, suggesting that DO might regulate

417 the pharmaceutical biotransformation cometabolically. It should be noted that the simulation

418 results are to provide insight into the potential impact of DO on pharmaceutical

419 biotransformation by enriched nitrifying culture rather than to accurately predict the reality,

420 which remain to be verified in future work.

421 The growth substrate might also have an impact on the pharmaceutical biotransformation.

422 Different ammonium concentrations ranging from 0 to $100 \mathrm{mg} \mathrm{L}^{-1}$ were applied in the model

423 simulations at different DO concentrations as shown in Figure 6. It was obvious that the 424 degradation efficiencies of studied pharmaceuticals and the formation rates of their 425 transformation products would increase dramatically when ammonium concentrations

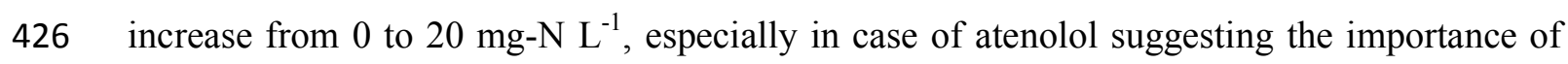
427 cometabolism on its biotransformation. However, there was no significant enhancement with 428 the increase of ammonium concentrations from 20 to $250 \mathrm{mg}-\mathrm{N} \mathrm{L}^{-1}$ (data of $100-250 \mathrm{mg}-\mathrm{N} \mathrm{L}^{-}$

$429{ }^{1}$ were not shown). This was contrary to the previous report where the removal efficiencies of 430 the selected pharmaceuticals were enhanced at higher initial ammonium concentrations. ${ }^{35}$ 431 This could be probably due to the substrate competition between growth substrate 432 (ammonium) and cometabolic substrates (e.g. atenolol or acyclovir). Pharmaceutical levels 433 applied in this study were several orders of magnitude lower than the investigated ammonium 434 concentrations, leading to a competition for AMO active sites and therefore potential 435 decreasing degradation rates at higher ammonium concentrations. ${ }^{31,33}$

436 In summary, a comprehensive model that considers all microbial processes contributing 437 to pharmaceutical biotransformation as well as the formation of biotransformation products 438 by the enriched nitrifying cultures is developed in this work. The proposed model was 439 successfully calibrated and validated using the biotransformation experiments of atenolol and 
440 acyclovir under different metabolic conditions. The linear positive correlation between

441 ammonia oxidation rate and pharmaceutical degradation rate confirmed the major role of 442 cometabolism induced by $\mathrm{AOB}$ in the pharmaceutical removal. DO was revealed to be 443 capable of regulating the pharmaceutical biotransformation cometabolically and the substrate 444 competition between ammonium and pharmaceuticals existed at high ammonium 445 concentrations. More verification should be conducted using other pharmaceuticals' 446 biotransformation data for this developed model to facilitate its application as a useful tool in 447 prediction of pharmaceutical fate, especially in the real municipal wastewater systems, where 448 other processes (e.g., the competition between different parent compounds on the enzyme 449 active sites) need to be considered in future work.

450

\section{Acknowledgement}

452 This study was supported by the Australian Research Council (ARC) through Future 453 Fellowship FT160100195. Dr. Bing-Jie Ni acknowledges the support of ARC Discovery 454 Project DP130103147.

455

456

\section{Supporting Information}

457 Additional texts, tables and figures are shown in Supporting Information.

\section{Reference}

460 (1) Ternes, T. A., Occurrence of drugs in German sewage treatment plants and rivers. Water 461 Res. 1998, 32 (11), 3245-3260.

(2) Benner, J.; Helbling, D. E.; Kohler, H. P. E.; Wittebol, J.; Kaiser, E.; Prasse, C.; Ternes, T. A.; Albers, C. N.; Aamand, J.; Horemans, B.; Springael, D.; Walravens, E.; Boon, N., Is biological treatment a viable alternative for micropollutant removal in drinking water treatment processes? Water Res. 2013, 47 (16), 5955-5976. 
466

(3) Petrie, B.; Barden, R.; Kasprzyk-Hordern, B., A review on emerging contaminants in wastewaters and the environment: Current knowledge, understudied areas and recommendations for future monitoring. Water Res. 2015, 72, 3-27.

(4) Evgenidou, E. N.; Konstantinou, I. K.; Lambropoulou, D. A., Occurrence and removal of transformation products of PPCPs and illicit drugs in wastewaters: A review. Sci. Total Environ. 2015, 505, 905-926.

(5) Carballa, M.; Omil, F.; Lema, J. M.; Llompart, M. a.; García-Jares, C.; Rodríguez, I.; Gómez, M.; Ternes, T., Behavior of pharmaceuticals, cosmetics and hormones in a sewage treatment plant. Water Res. 2004, 38, (12), 2918-2926.

(6) Batt, A. L.; Kim, S.; Aga, D. S., Enhanced biodegradation of iopromide and trimethoprim in nitrifying activated sludge. Environ. Sci. Technol. 2006, 40 (23), 7367-7373.

(7) Yi, T.; Harper Jr, W. F., The link between nitrification and biotransformation of $17 \alpha$ ethinylestradiol. Environ. Sci. Technol. 2007, 41 (12), 4311-4316.

(8) Keener, W. K.; Arp, D. J., Kinetic studies of ammonia monooxygenase inhibition in Nitrosomonas europaea by hydrocarbons and halogenated hydrocarbons in an optimized whole- cell assay. Appl. Environ. Microbiol. 1993, 59 (8), 2501-2510.

(9) Keener, W. K.; Arp, D. J., Transformations of aromatic compounds by Nitrosomonas europaea. Appl. Environ. Microbiol. 1994, 60 (6), 1914-1920.

(10) Xu, Y.; Yuan, Z.; Ni, B.-J., Biotransformation of pharmaceuticals by ammonia oxidizing bacteria in wastewater treatment processes. Sci. Total Environ. 2016, 566-567, 796-805.

(11) Tran, N. H.; Urase, T.; Ngo, H. H.; Hu, J.; Ong, S. L., Insight into metabolic and cometabolic activities of autotrophic and heterotrophic microorganisms in the biodegradation of emerging trace organic contaminants. Bioresour. Technol. 2013, 146, (0), 721-731.

(12) Quintana, J. B.; Weiss, S.; Reemtsma, T., Pathways and metabolites of microbial degradation of selected acidic pharmaceutical and their occurrence in municipal wastewater treated by a membrane bioreactor. Water Res. 2005, 39 (12), 2654-2664.

(13) Fernandez-Fontaina, E.; Carballa, M.; Omil, F.; Lema, J. M., Modelling cometabolic biotransformation of organic micropollutants in nitrifying reactors. Water Res. 2014, 65, 371-383.

(14) Oldenhuis, R.; Vink, R. L. J. M.; Janssen, D. B.; Witholt, B., Degradation of chlorinated aliphatic hydrocarbons by Methylosinus trichosporium OB3b expressing soluble methane monooxygenase. Appl. Environ. Microbiol. 1989, 55 (11), 2819-2826.

(15) Liu, L.; Binning, P. J.; Smets, B. F., Evaluating alternate biokinetic models for trace pollutant cometabolism. Environ. Sci. Technol. 2015, 49 (4), 2230-2236.

(16) Verlicchi, P.; Al Aukidy, M.; Zambello, E., Occurrence of pharmaceutical compounds in urban wastewater: Removal, mass load and environmental risk after a secondary treatment-A review. Sci. Total Environ. 2012, 429, 123-155. 
508

509

510

511

512

513

514

515

516

517

518

519

520

521

522

523

524

525

526

527

528

529

530

531

532

533

534

535

536

537

538

539

540

541

542

543

544

(17) Prasse, C.; Schlüsener, M. P.; Schulz, R.; Ternes, T. A., Antiviral drugs in wastewater and surface waters: a new pharmaceutical class of environmental relevance? Environ. Sci. Technol. 2010, 44 (5), 1728-1735.

(18) Prasse, C.; Wagner, M.; Schulz, R.; Ternes, T. A., Biotransformation of the antiviral drugs acyclovir and penciclovir in activated sludge treatment. Environ. Sci. Technol. 2011, 45 (7), 2761-2769.

(19) Radjenović, J.; Pérez, S.; Petrović, M.; Barceló, D., Identification and structural characterization of biodegradation products of atenolol and glibenclamide by liquid chromatography coupled to hybrid quadrupole time-of-flight and quadrupole ion trap mass spectrometry. J. Chromatogr. A 2008, 1210 (2), 142-153.

(20) Sathyamoorthy, S.; Chandran, K.; Ramsburg, C. A., Biodegradation and cometabolic modeling of selected beta blockers during ammonia oxidation. Environ. Sci. Technol. 2013, 47 (22), 12835-12843.

(21) Xu, Y.; Yuan, Z.; Ni, B.-J., Impact of Ammonium Availability on Atenolol Biotransformation during Nitrification. ACS Sustainable Chem. Eng. 2017, 5 (8), $7137-$ 7144.

(22) Xu, Y.; Yuan, Z.; Ni, B.-J., Biotransformation of acyclovir by an enriched nitrifying culture. Chemosphere 2017, 170, 25-32.

(23) Ginestet, P.; Audic, J. M.; Urbain, V.; Block, J. C., Estimation of nitrifying bacterial activities by measuring oxygen uptake in the presence of the metabolic inhibitors allylthiourea and azide. Appl. Environ. Microbiol. 1998, 64 (6), 2266-2268.

(24) Ali, T. U.; Kim, M.; Kim, D. J., Selective inhibition of ammonia oxidation and nitrite oxidation linked to n2o emission with activated sludge and enriched nitrifiers. $J$. Microbiol. Biotechnol. 2013, 23 (5), 719-723.

(25) Xu, Y.; Radjenovic, J.; Yuan, Z.; Ni, B. J., Biodegradation of atenolol by an enriched nitrifying sludge: Products and pathways. Chem. Eng. J. 2017, 312, 351-359.

(26) Kasim, N. A.; Whitehouse, M.; Ramachandran, C.; Bermejo, M.; Lennernäs, H.; Hussain, A. S.; Junginger, H. E.; Stavchansky, S. A.; Midha, K. K.; Shah, V. P.; Amidon, G. L., Molecular properties of WHO essential drugs and provisional biopharmaceutical classification. Mol. Pharmaceutics 2004, 1 (1), 85-96.

(27) Maurer, M.; Escher, B. I.; Richle, P.; Schaffner, C.; Alder, A. C., Elimination of $\beta$ blockers in sewage treatment plants. Water Res. 2007, 41 (7), 1614-1622.

(28) Mohsen-Nia, M.; Ebrahimabadi, A. H.; Niknahad, B., Partition coefficient noctanol/water of propranolol and atenolol at different temperatures: Experimental and theoretical studies. J. Chem. Thermodyn. 2012, 54, 393-397.

(29) Küster, A.; Alder, A. C.; Escher, B. I.; Duis, K.; Fenner, K.; Garric, J.; Hutchinson, T. H.; Lapen, D. R.; Péry, A.; Römbke, J.; Snape, J.; Ternes, T.; Topp, E.; Wehrhan, A.; Knackerk, T., Environmental risk assessment of human pharmaceuticals in the European union: A case study with the $\beta$-blocker atenolol. Integr. Environ. Assess. Manage. 2010, 6 (SUPPL. 1), 514-523. 
545

548

549

550

551

552

553

554

555

556

557

558

559

560

561

562

563

564

565
(30) Batstone, D. J.; Pind, P. F.; Angelidaki, I., Kinetics of thermophilic anaerobic oxidation of straight and branched chain butyrate and valerate. Biotechnol. Bioeng. 2003, 84 (2), 195-204.

(31) Fernandez-Fontaina, E.; Omil, F.; Lema, J. M.; Carballa, M., Influence of nitrifying conditions on the biodegradation and sorption of emerging micropollutants. Water Res. 2012, 46 (16), 5434-5444.

(32) Men, Y.; Han, P.; Helbling, D. E.; Jehmlich, N.; Herbold, C.; Gulde, R.; OnnisHayden, A.; Gu, A. Z.; Johnson, D. R.; Wagner, M.; Fenner, K., Biotransformation of Two Pharmaceuticals by the Ammonia-Oxidizing Archaeon Nitrososphaera gargensis. Environ. Sci. Technol. 2016, 50 (9), 4682-4692.

(33) Dawas-Massalha, A.; Gur-Reznik, S.; Lerman, S.; Sabbah, I.; Dosoretz, C. G., Cometabolic oxidation of pharmaceutical compounds by a nitrifying bacterial enrichment. Bioresour. Technol. 2014, 167, 336-342.

(34) Helbling, D. E.; Johnson, D. R.; Honti, M.; Fenner, K., Micropollutant biotransformation kinetics associate with WWTP process parameters and microbial community characteristics. Environ. Sci. Technol. 2012, 46 (19), 10579-10588.

(35) Tran, N. H.; Urase, T.; Kusakabe, O., The characteristics of enriched nitrifier culture in the degradation of selected pharmaceutically active compounds. J. Hazard. Mater. 2009, 171 (1-3), 1051-1057. 
568 Table 1. Estimated parameter values for the biotransformation model in this study

Figure 1. Model calibration with experimental data from atenolol biodegradation: (A)

571 Experiment 1, with addition of allylthiourea (ATU); (B) Experiment 2, in the absence of 572 ammonium; and (C) Experiment 3, in the presence of ammonium $\left(50 \mathrm{mg} \mathrm{NH}_{4}{ }^{+}-\mathrm{N} \mathrm{L}^{-1}\right)$.

573

576

577

578

579

580

581

582

583

584

585

586

587

588

589

590

591

592

Figure 2. Model validation results of atenolol biotransformation by the enriched nitrifying culture in the presence of ammonium of $25 \mathrm{mg}-\mathrm{N} \mathrm{L}^{-1}$ (Experiment 4).

Figure 3. Model evaluation with experimental data from acyclovir biodegradation: (A) Experiment 1, with addition of allylthiourea (ATU), (B) Experiment 2, in the absence of ammonium and (C) Experiment 3, in the presence of ammonium (50 $\left.\mathrm{mg} \mathrm{NH}_{4}^{+}-\mathrm{N} \mathrm{L}^{-1}\right)$.

Figure 4. (A) The relationship between ammonia oxidizing rate and the pharmaceutical degradation rates in terms of atenolol and acyclovir (black solid squares indicate the atenolol degradation rates after $240 \mathrm{~h}$ ); and (B) The relationship between ammonia oxidizing rate and the acyclovir degradation rate after $240 \mathrm{~h}$ at a different linear fit slope.

Figure 5. Predicted final concentrations of (A) atenolol and atenolol acid and (B) acyclovir and carboxy-acyclovir at time of $240 \mathrm{~h}$ at different concentrations of dissolved oxygen (DO) in the enriched nitrifying culture system.

Figure 6. Predicted concentrations of pharmaceuticals and their transformation products at time of $240 \mathrm{~h}$ at initial concentrations of $15 \mu \mathrm{g} \mathrm{\textrm {L } ^ { - 1 }}$ with different ammonium concentrations ranging from 0 to $100 \mathrm{mg}-\mathrm{N} \mathrm{L}^{-1}$ at different DO levels. 
Table 1. Estimated parameter values for the biotransformation model in this study

\begin{tabular}{|c|c|c|c|c|}
\hline \multirow{2}{*}{ Parameters } & \multirow{2}{*}{ Definition } & \multirow{2}{*}{ Unit } & \multicolumn{2}{|c|}{ Estimated } \\
\hline & & & atenolol & acyclovir \\
\hline$k_{P C-H E T}$ & $\begin{array}{l}\text { Heterotrophs (HET) transformation } \\
\text { coefficient }\end{array}$ & $\mathrm{m}^{3} \mathrm{~g} \mathrm{COD}^{-1} \mathrm{~h}^{-1}$ & $\begin{array}{c}0.000180 \\
\pm \\
0.000017\end{array}$ & $\begin{array}{l}0.00035 \pm \\
0.00002\end{array}$ \\
\hline$k_{P C-A O B}$ & $\begin{array}{l}\text { Ammonia oxidizing bacteria (AOB) } \\
\text { transformation coefficient }\end{array}$ & $\mathrm{m}^{3} \mathrm{~g} \mathrm{COD}^{-1} \mathrm{~h}^{-1}$ & $\begin{array}{c}0.000140 \\
\pm \\
0.000012\end{array}$ & $\begin{array}{l}0.00005 \pm \\
0.00003\end{array}$ \\
\hline$T_{P C-A O B}^{c}$ & $\begin{array}{l}\text { Parent compound biotransformation } \\
\text { coefficient rate linked to AOB } \\
\text { growth (cometabolism) }\end{array}$ & $\mathrm{m}^{3} \mathrm{~g} \mathrm{COD}^{-1}$ & $\begin{array}{c}0.012 \pm \\
0.000036\end{array}$ & $\begin{array}{l}0.00093 \pm \\
0.00049\end{array}$ \\
\hline$\mu_{\max , A O B}$ & $\begin{array}{l}\text { Maximum specific growth rate of } \\
\text { AOB }\end{array}$ & $\mathrm{h}^{-1}$ & 0.012 & 0.0023 \\
\hline
\end{tabular}

594 

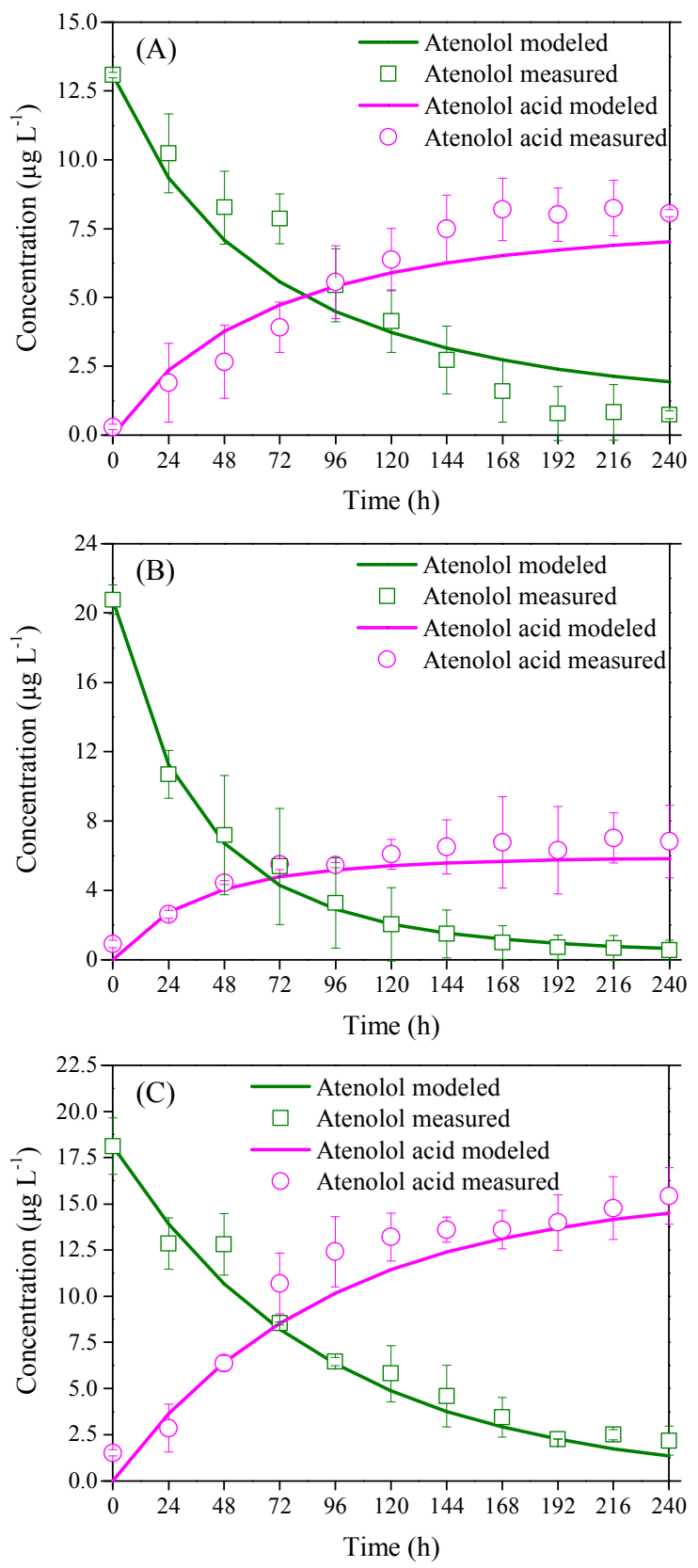

595

596 Figure 1. Model calibration with experimental data from atenolol biodegradation: (A)

597 Experiment 1, with addition of allylthiourea (ATU); (B) Experiment 2, in the absence of

598 ammonium; and (C) Experiment 3, in the presence of ammonium $\left(50 \mathrm{mg} \mathrm{NH}_{4}{ }^{+}-\mathrm{N} \mathrm{L}^{-1}\right)$. 


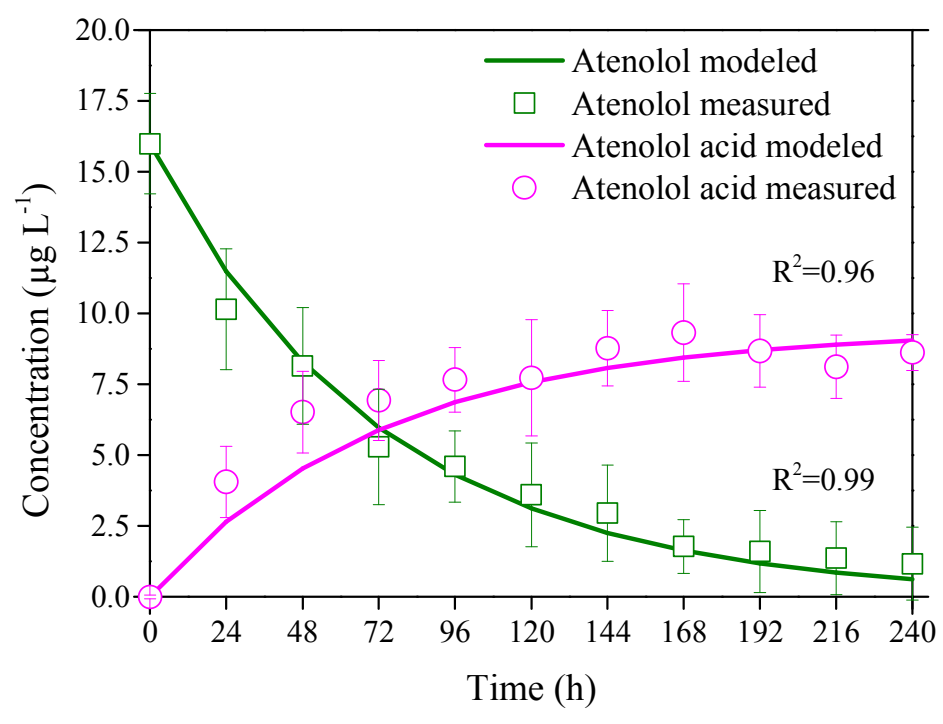

601 Figure 2. Model validation results of atenolol biotransformation by the enriched nitrifying 602 culture in the presence of ammonium of $25 \mathrm{mg}^{-\mathrm{N} \mathrm{L}^{-1}}$ (Experiment 4). 

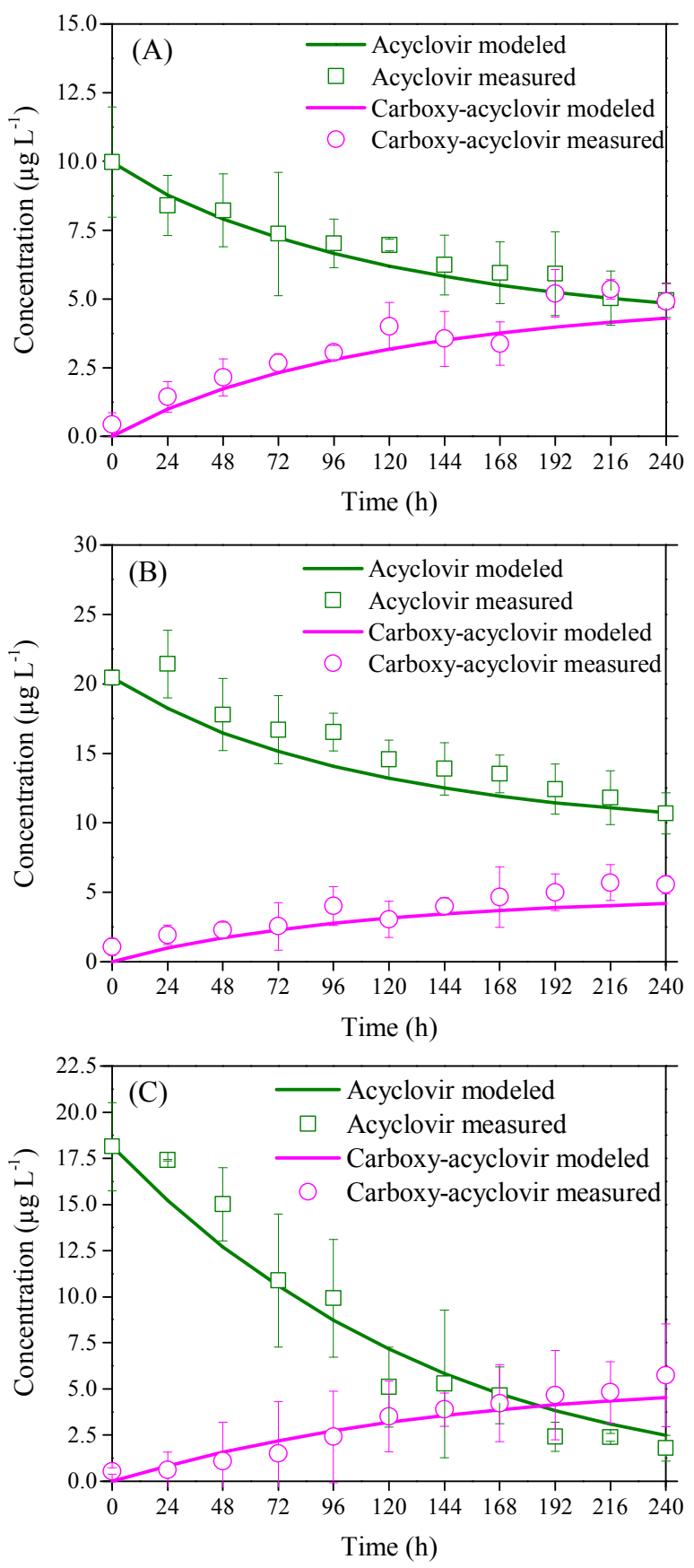

606 Figure 3. Model evaluation with experimental data from acyclovir biodegradation: (A)

607 Experiment 1, with addition of allylthiourea (ATU), (B) Experiment 2, in the absence of 608 ammonium and (C) Experiment 3, in the presence of ammonium $\left(50 \mathrm{mg} \mathrm{NH}_{4}{ }^{+}-\mathrm{N} \mathrm{L}^{-1}\right)$. 

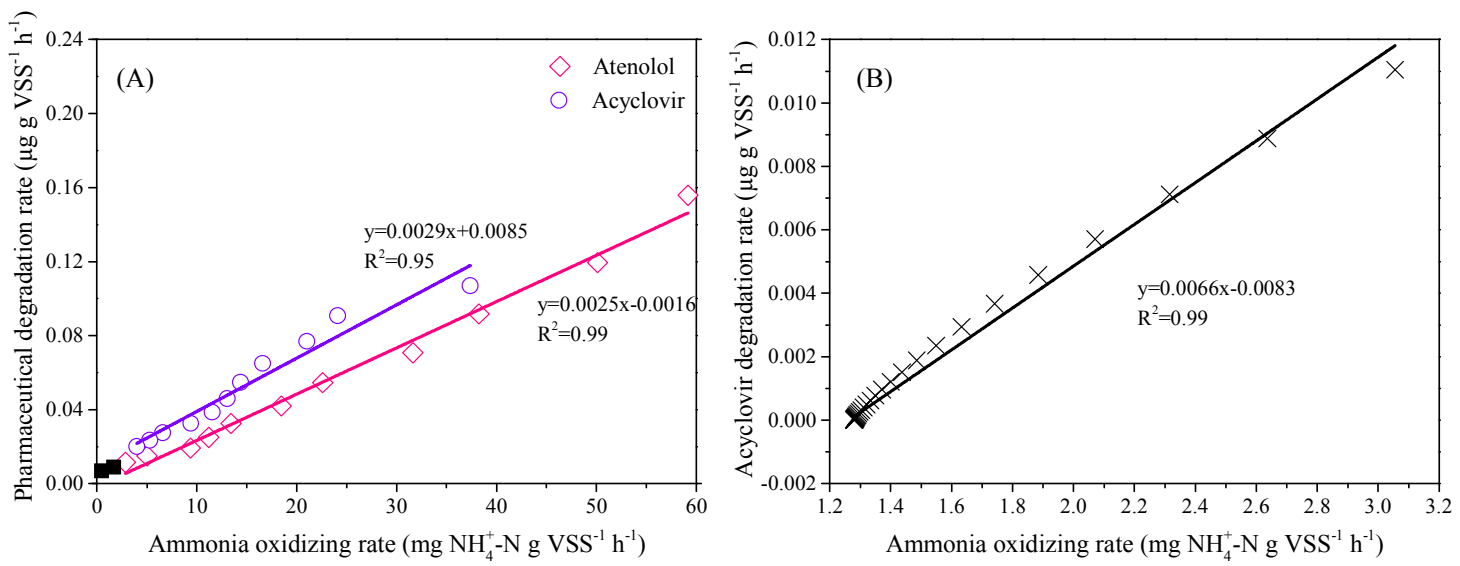

Figure 4. (A) The relationship between ammonia oxidizing rate and the pharmaceutical

611 degradation rates in terms of atenolol and acyclovir (black solid squares indicate the atenolol

612 degradation rates after $240 \mathrm{~h}$ ); and (B) The relationship between ammonia oxidizing rate and

613 the acyclovir degradation rate after $240 \mathrm{~h}$ at a different linear fit slope. 
614

(A)

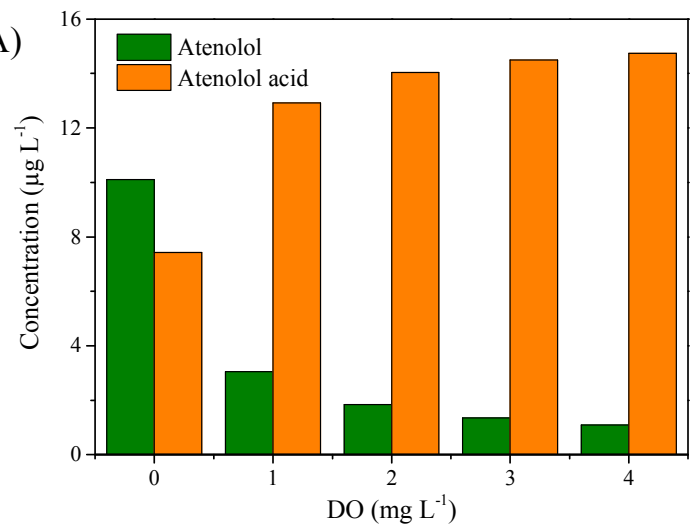

(B)

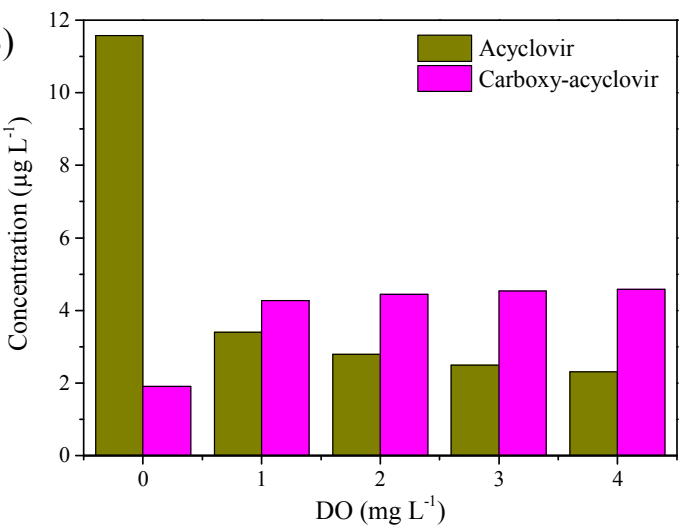

615 Figure 5. Predicted final concentrations of (A) atenolol and atenolol acid and (B) acyclovir

616 and carboxy-acyclovir at time of $240 \mathrm{~h}$ at different concentrations of dissolved oxygen (DO)

617 in the enriched nitrifying culture system. 

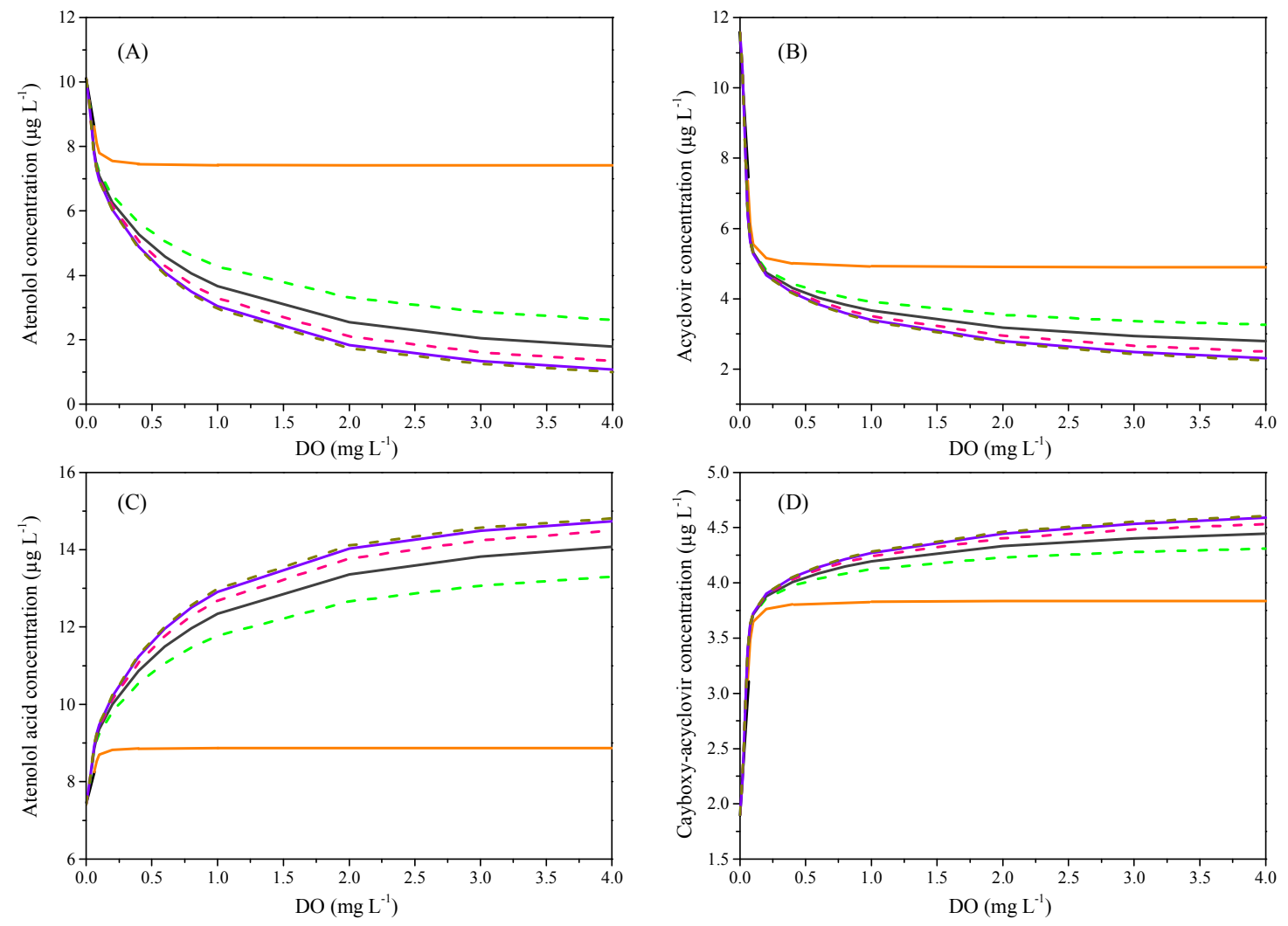

618

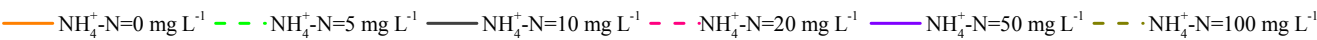

619 Figure 6. Predicted concentrations of pharmaceuticals and their transformation products at

620 time of $240 \mathrm{~h}$ at initial concentrations of $15 \mu \mathrm{g} \mathrm{L}^{-1}$ with different ammonium concentrations

621 ranging from 0 to $100 \mathrm{mg}-\mathrm{N} \mathrm{L}^{-1}$ at different DO levels. 